\title{
The Turnovers Analysis to the Women's National League Basketball Games
}

\author{
Anastassia FYLAKTAKIDOU ${ }^{1} \bullet$ Evangelos TSAMOURTZIS $^{2}$ \\ Georgios ZAGGELIDIS ${ }^{3}$
}

7 he purpose of this study was to describe and analyze the turnovers efficacy to the result of a basketball game. For the purpose of this study forty-three $(n=43)$ women A1 National league basketball games were videotaped and video-analyzed. Statistical analysis of this data included the presentation of frequencies in a double table and the application of $\mathrm{x} 2$. The results showed that a) 19,1\% of the possessions stop after a turnover, b) the most common turnover to the women basketball is the passing errors (40,2\%). Travelling $(23,6 \%)$ and fault ball handling (23,9\%) follow, c) most of the turnovers happen during the set play, d) most of the fault passes take place from the area around the three point line to the opposite base line, most of the traveling and the fault ball handling to the area around the basket and inside the three point line, e) the ability to defeat the zone defense is of a real importance because the women basketball teams use to play this defense and most of the turnovers seems to happen under these circumstances (winners $16,5 \%$ - losers $22,2 \%)$.

Keywords: Basketball, turnover, videoanalysis

\section{Introduction}

The turnovers, shots and fouls constitute the effectiveness of offense (Mikes 1988). According to Mikes (1987), turnovers occur more often than you might imagine, especially taking into account the level of skills of today's players. Their display frequencies, is the main culprit for the reduction of offensive percentage, and even more than the percentage of shots and rebounds. The minimizing of turnovers should be the main concern of the offense to achieve a victory.

\footnotetext{
${ }^{1}$ University of Ioannina, Greece

${ }^{2}$ Department of Physical Education and Sport Sciences, Democritus University of Thrace, Greece

${ }^{3}$ Department of Physical Education and Sport Sciences, Aristotle University, Thessaloniki, Greece
} 
According to Kioumourtzoglou Taxildari and Tsitskari (1994), there's no point to achieve a scoring percentage of $65 \%$, if the three times a team gains possession of the ball while on defense, the team, at least once, loses the ball trying to bring it down for a shot. A possession that ends up in turnovers, has as a result, the ball ending up in the opponents hands, without a shot ever taken or to win a foul (Mikes 1987).

According to Dean, (1997), there are in general differences in the way a women's team plays compared to the men's team, which needs to be systematically studied and at a scientific level, so that it can achieve improvement and progress. There is research that refers to women's basketball, which concerns the recordings, mainly technical data (Theoxaropoulos, Tsitskaris, Garefis, 2002), as well as psychological and fitness levels (DiNucci, Finkenberg, McCune, McCune, Mayo, 1994). Certain others, have to do with the comparison between men and women and the shooting ability (Elliot, 1992; Looney, Spray, Castelli, 1996; Tsitskaris, Theoxaropoulos, Vamvakoudis, Nikopoulou, 2001).

The women's team presents a higher percentage of turnovers in their game, in relations to the men's team (Tsamourtzis, Filaktakidou, Arvanitidou, Ellinoudis, Taxildaris, 1998). The written records for turnovers, are limited mainly to the report of percentage appearance for each game (Tsamourtzis, Fylaktakidou \& Taxildaris, 2001; Mavridis, Laios, Taxildaris \& Tsiskaris, 2003; Polykratis, Tsamourtzis, Karypidis, Mavridis \& Christodoulos, 2009; Mavridis, Tsamourtzis, Karidpidis, Laios, 2009)

The game of basketball is multifunctional and demands systematic and an in-depth research of all parameters (offense tactics, the way to demonstrate offense, defense tactics, etc.), as well as the way these parameters are connected between them during the game. There's a research gap, as far as the recordings and tactic and technical data processing and interaction analysis are concerned, in female teams (Filaktakidou, Tsamourtzis, Taxildaris, 2003). The written report, exclusively for the practical part of the sport (offensive and defensive systems and exercises for practice) covers up to now the coaches training needs (Tsitskaris et al., 2001).

This research was done with the aim of covering a small gap that exists in women's basketball, as far as the recording and the analysis of turnovers and their role in shaping the outcome. Also, it was to study the interaction of turnovers in game situations (offensive tactics, the distance from the basket where the turnovers was made, defense tactics). The results of the research will offer new information to the women's coach, which will help improve the effectiveness of the offense, and better organized practices. 


\section{Methodology}

Sample: The sample made possible for the research, constituted of fortythree ( $\mathrm{n}=43$ ) basketball games, A1 National women's division, the Greek Championship, where done during game seasons 2005-2010. The choice of this sample was at random, as the number of teams whose games were videotaped is short and sporadic and television coverage of women's basketball is limited.

Equipment. The method of indirect observation was employed and the following equipment were used:

- Video and DVD \pm RW for the recording of the games.

- Computer $(\mathrm{P} / \mathrm{C})$

- "Sportscout" program for the analysis of the digital video (Tsimpiris, Tsamourtzis, Sfingos, Zaggelidis G., Zaggelidis S., 2006).

Process: A video analysis took place for the accomplishment of the work's purpose. The comparisons occurred between winners and losers and there were studied the display frequencies of the following parameters:

1. The team who demonstrated offense: the winner, the loser (the outcome of the game was known).

2. The way offense was demonstrated: shots, turnovers, fouls.

3. An analysis of types of turnovers: passing turnovers, traveling, ball handling errors, ball returned to the backcourt, (three, five, eight, twenty-four) seconds rule, double dribbling, offensive foul.

4. Offensive tactics: fast break, early offense, set play.

5. The distance from the basket where the turnover was made: restricted area (the area under the basket), perimeter (the area away from the basket and inside the three-point line), three-point area (the area around the three-point line), mid-court (the area outside the three-point line to the area outside the three-point line of the opposing team), backcourt (the area from the end line to outside the three-point area of the opposing team). (fig.1)

6. Defense tactics: man to man, man to man trapping, zone, trap zone, mixed defenses, defensive transition. 
After the completion of the above mentioned protocol, an observation of the game followed, through a PC and the simultaneous recording of observed cases (Encoding), on a table of observation protocol. This table constituted the final data table, which in continuation was processed statistically. The registration of the data was carried out by the researcher herself, in a University, Video-analysis Department. For the reliability of the measurements, the first ten matches were analyzed twice. Spearman's Correlation Test and Wilcoxon's Nonparametric Test were performed. Spearman's Correlation Test revealed that all variables had a statistically important, positive correlation. Wilcoxon's Nonparametric Test, 2 Related Samples, did not reveal any statistically important differences for the same variables, either.

Data Analysis: The statistic analysis package SPSS was used for the statistic analysis of the data. The statistic analysis non-parametric test $\mathrm{x} 2$ (chi-square) with level of importance $p<.05$ used to determine the possible relationship between seven (7) different types of turnovers (passing errors, traveling, ball handling errors, ball returned to the backcourt, (three, five, eight, twenty-four) seconds rule, double dribbling, offensive foul) with the result of the game. In counting the cases, for every combination of action the independent variable was the result of the game and the dependent variable was the type of turnover. Similarly examined if the result of the game influenced from the comparison between turnovers and offensive tactics, as well as the distance from the basket where the turnover was made. In counting cases, for every combination of action the independent variable was the result of the game and the dependent was the offensive tactic and the distance from the basket where the turnover was made. Then, it was evaluated to see if the type of turnover was affected from the area of the court where it happened. In counting the cases, for every combination of action the independent variable was the type of turnover and the dependent variable was the distance from the basket where the turnover was made. Finally, an evaluation was done on the turnovers made in relations to the defense tactic, and if it affected the result of the game. In counting the cases, for every combination of action, the independent variable was the result of the game and the dependent was the defense tactic. To check the consistency of rates which appeared from each combination of actions, this was made possible through the statistical criterion Chi-square.

\section{Results}

Examining the sample of the way offense is demonstrated as a whole, we found that offensive plays were interrupted by turnover at a $19.1 \%$. Shooting $(59.5 \%)$ is the common way to demonstrate offense, followed by fouls $(21.4 \%)$ and then turnovers. 
In relations to the type of turnovers that occur during the game, the results showed that most of the offense was interrupted by passing errors $(40,2 \%)$ (Table 1). After the passing errors the offense was interrupted by ball handling errors $(23.9 \%)$ and travelling $(23,6 \%)$. Then followed the offensive fouls $(8.6 \%)$ and only $3.7 \%$ has to do with the rest of the turnovers (ball returned to the backcourt, turnover seconds, double dribbling). The x2 (Chi-square) spread showed that there is independence in the distribution of value of variables: $\mathrm{x} 2=$ $.04<.05$. According to the value $\mathrm{x} 2$ we found that wrong ball passing happens more often in a game than any other type of turnovers, so much from the winners $[\mathrm{x} 2(12.59)=477.24]$, as from the losers $[\mathrm{x} 2(12,59)=617.9]$.

The basis for the analysis of the non-parametric test $\mathrm{x} 2$ (chi-square) found that a win is affected by ball handling errors $[\mathrm{x} 2(3.84)=7.27]$. On the contrary, the results didn't show statistically major changes for passing errors $[\mathrm{x} 2(3.84)$ $=2.43]$, traveling $[\mathrm{x} 2(3.84)=0.03]$, turnover seconds $[\mathrm{x} 2(3.84)=0.03$, double dribbling $[\mathrm{x} 2(3.84)=3]$ and offensive fouls $[\mathrm{x} 2(3.84)=1.5]$. It seems that the winners made more "ball returned to the backcourt" turnovers in a statistically major difference $[\mathrm{x} 2(3.84)=5]$. They can't though draw conclusions because of the low frequency of this turnover. With a comparison between winners and losers, we found that the winners actually had less turnovers $(47.4 \%)$, without a statistically major difference $[\mathrm{x} 2(3.84)=2.91]$. 
The Turnovers Analysis in Women's Basketball

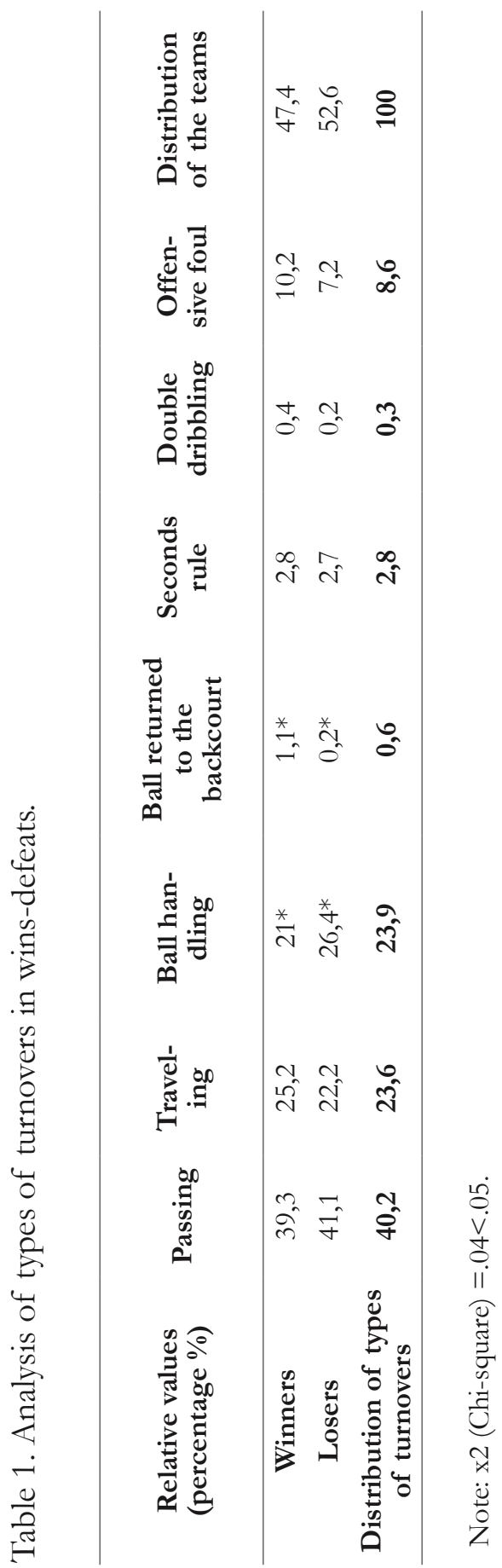


Having examined how much turnovers are affected by the offense tactics (fast break, early offense, set play), the $\mathrm{x} 2$ (Chi-square) distribution showed that there is not independence in the spread value of variables $\times 2=.32>.05$. With the comparison between fast break and set play, it shows that most turnovers are made in set play $(81.8 \%)$. Having studied the percentage that represents the turnovers in offense, found that there are more turnovers in the set play: winners: (fast break $12.5 \%$, early offense $5 \%$, set play $19.8 \%$ ) losers: (fast break $16.4 \%$, early offense $26.3 \%$, set play $21.4 \%$ ). We found that the losers showed higher percentage of turnover in the early offense. The statistical analysis showed that there was a statistically significant difference between fast break, early offense and set play $\times 2(5.99)=1220.63$. With the comparison between winners and losers, we found that there was no difference: fast break $[\mathrm{x} 2(3.84)=0.71]$, early offense $[\mathrm{x} 2(3.84)=2.66]$, set play $[\mathrm{x} 2(3.84)=1.85]$.

For the area pinpointed on the court where possibly more turnovers occurred, we created five zones (restricted area, perimeter area, three point area, mid court, backcourt) (Figure 1) These zones represent the distance in relations to the basket, where the turnovers were made.

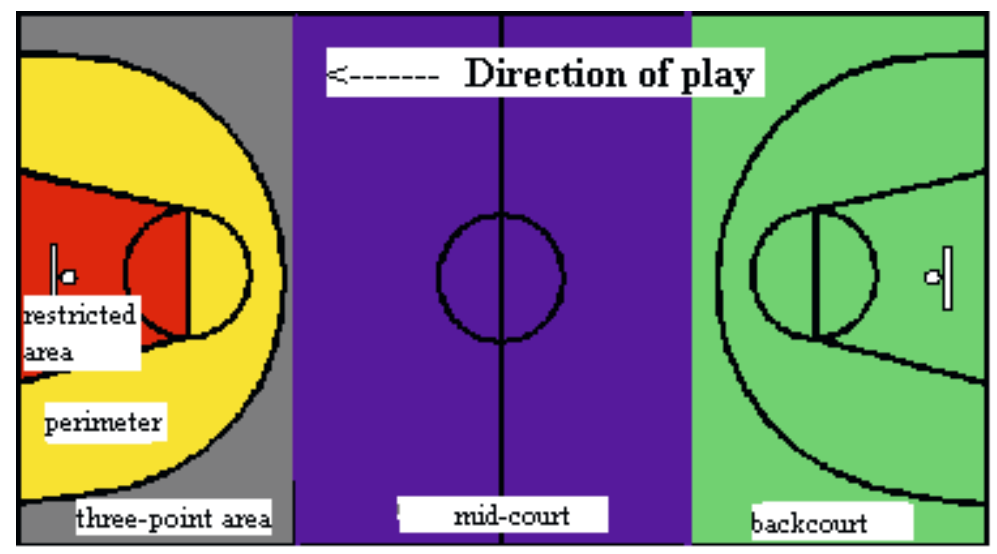

Figure 1. Areas on the court where turnovers are made

Most of the mistakes were made in the perimeter area (Table 2) with a percentage of $(44.2 \%)$ and followed by the three-point area $(22.9 \%)$ and last is the restricted area $(14.3 \%)$. Significantly, $(81.4 \%)$ of turnovers were found in the perimeter around the basket. The mid-court area (10.7\%) and the backcourt area $(7.9 \%)$ appeared lower in percentage. The basis for the analysis of the non-parametric test $\mathrm{x} 2$ (chi-square) found that the area of the court where the offense is 
carried out has affected the turnovers made, so much from the winners [x2(9.48) $=10.89]$, as from the losers $[\mathrm{x} 2(9.48)=18.76]$.

Table 2. The areas of the court where the turnovers were made in wins-defeats.

\begin{tabular}{ccccccc}
\hline $\begin{array}{c}\text { Relative values } \\
\text { (percentage } \\
\text { \%) }\end{array}$ & $\begin{array}{c}\text { Restricted } \\
\text { area }\end{array}$ & $\begin{array}{c}\text { Perim- } \\
\text { eter }\end{array}$ & $\begin{array}{c}\text { Three- } \\
\text { point area }\end{array}$ & Mid-court & $\begin{array}{c}\text { Back- } \\
\text { court }\end{array}$ & $\begin{array}{c}\text { Distribution } \\
\text { of the teams }\end{array}$ \\
\hline Winners & 14,6 & 45,6 & 22,9 & 10,8 & $6,1 *$ & 47,4 \\
$\begin{array}{c}\text { Losers } \\
\begin{array}{c}\text { Distribution } \\
\text { of the areas of } \\
\text { the court }\end{array}\end{array}$ & $\mathbf{1 4}$ & 42,9 & 22,9 & 10,6 & $9,6^{*}$ & 52,6 \\
\hline
\end{tabular}

Note: Winners: $\mathrm{x} 2(9,48)=10,89$, Losers: $\mathrm{x} 2(9,48)=18,76$.

Having examined the hypothesis that in specific areas of the court, some types of turnovers happen more frequently in relations to other areas of the court (Table 3), we found that from the area outside the three-point line to the backcourt area on the offense side, it is where most of the passing errors are found. In the three-point area, the passing errors make up $(70.2 \%)$, whereas traveling $(7.8 \%)$, ball handling mistakes $(16.5 \%)$, turnover seconds $(3.6 \%)$, double dribbling $(0.4 \%)$ and offensive fouls $(1.5 \%)$. In the mid-court area, passing errors make up $(44.6 \%)$, whereas traveling $(9.2 \%)$, ball handling errors $(29.4 \%)$, ball returned to the backcourt $(5.9 \%)$, turnover seconds $(8.4 \%)$, double dribbling $(0.8 \%)$ and offensive fouls $(1.7 \%)$. In the backcourt area, the passing errors make up $(55.7 \%)$ whereas traveling $(4.5 \%)$, ball handling errors $(37.5 \%)$ and offensive fouls $(2.3 \%)$. The $\mathrm{x} 2$ (Chi-Square) spread showed that there was independence in the spread value of the variable: $\mathrm{x} 2=.00<.05$. 
Sport Science Review, vol. XX, No. 3-4, August 2011

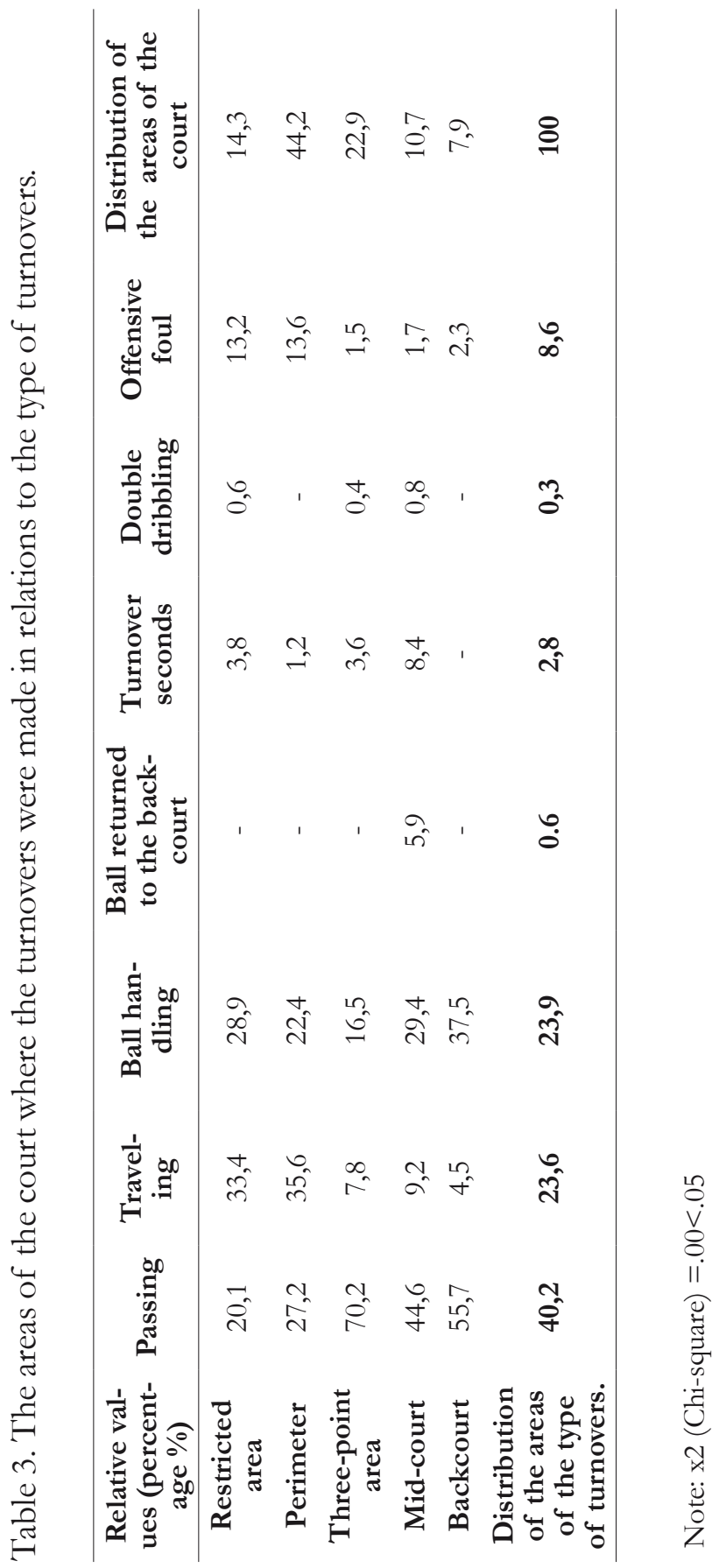


Having examined the relation between turnovers and defense tactics, the x2 (Chi-square) spread showed that there was independence in the spread value of the variable: $\mathrm{x} 2=.04<.05$, and therefore the win was affected by the defense tactic in relations to the turnovers.

With the comparison between the winner and loser, we found that there was no statistically significant difference in the turnovers that were made against man to man defense $[\mathrm{x} 2(3.84)=0.12]$, trap zone $[\mathrm{x} 2(3.84)=0]$, mixed defense $[\mathrm{x} 2(3.84)=2]$ and defensive transition $[\mathrm{x} 2(3.84)=0.55]$. On the contrary, the turnovers made against man to man trapped defense $[\mathrm{x} 2(3.84)=7.36]$ and against zone defense, $[\mathrm{x} 2(3.84)=4.59]$ affected the outcome of the game. The above mentioned also observing the percentages that winners and losers appeared proportionally, in all defenses. More analytically, winners and losers made similar percentages of turnover against man to man defense (winners: $20.5 \%$ - losers: $20 \%$ ), in the trap zone (winners: $25 \%$ - losers: $22.2 \%$ ) and in mixed defense (winners: $10 \%$ - losers: $11.7 \%$ ) The losers faced difficultly in coping with the defense zone (winners: $16.3 \%$ - losers: $22.2 \%$ ) and man to man traps (winners: $10 \%$ - losers: $41.6 \%$ ), where it showed a higher percentage in comparison to the winners. Finally, the losers showed a higher percentage from the winners in the defensive transition, that is to say defense plays that started out of turnover in the offense and ended up fast breaking the opponent (winners: 16.5\% - losers: 19.5\%).

\section{Discussion}

From the results of the present research, we found that the display frequency in turnovers (19.1\%) in women's basketball teams was higher in relations to what is mentioned in the bibliography (14\%) and concerns men's teams (Greek Championship, National Team, European teams and NBA teams) (Mikes, 1987; Tsamourtzis et. al.,1998). The possible cause was to constitute the different levels of ability of the women's team (Dean, 1997). In this event, more specific emphasis should be given from the coaches, as according to the bibliography, the controlled number of turnovers makes up the requirements needed for the win (Mikes, 1988). According to Kioumourtzoglou et. al (1994) of course, one main offensive goal is for the team to make less than ten turnovers per game.

The most common display of turnover was passing (40.2\%). This fact probably is due to two reasons. First, for the last couple of years, a control offense tactic has been followed, resulting in an increase of the number of passes. According to Mikes (1987), the more the team works the ball before the shot, the more the chances of a turnover occurring. Second, passing is the quickest way to transfer the ball down the court. At the same time however, in order for it to become precise in the transfer and working together between the players, factors 
which is likely due to the increased possibility of turnover. (Anastasiadis, 1995). Perfection in execution passing means a reduction in turnovers, consequently less risk and more chances of effectiveness for a team (Theoxaropoulos et. al 2002).

After passing errors, the display frequency shown, that followed the ball handling errors $(23.9 \%)$ and traveling $(23.6 \%)$. A different picture shows the men's team where ball handling errors (34\%), and passing errors $(33 \%)$ are the main turnovers (Tsamourtzis et. al.,1998). From the above mentioned, it seems that the women's teams are more prone to passing errors than the men's. Taking into consideration that skills play a major role in executing the passes (Theoxaropoulos et.al, 2002), and the team that's able to manage to control the rhythm of the offense using the effectiveness of passing, has more chances of finding themselves in a better shooting position (Kundstadt, 1994; Stavropoulos, Gerodimos, Tzouvaris, Kellis, 2001), the coaches should give more emphasis on improving the ability of this, with more systematical practice. On the contrary on ball handling, seems that women's teams are more effective. This may be due to the fact that the defense of the women's teams isn't particularly pressing therefore balling handling is easier.

From the above mentioned results, we found that when fast break, less turnovers occur in relations to set play. Mikes (1988) agrees with this. His work concerned America's college championship, and found that as far as the turnovers in set play are concerned, they make up $17.2 \%$ of the total organized attacks, whereas in fast break they make up $14.2 \%$. From this present work, we found that the losers proportionally showed in the attacks total, a much higher percentage of turnover in the early offense $(26.3 \%)$ in relations to the winners $(5 \%)$. This fact is possibly due to a lower degree of readiness of a team in the early offense. The coaches should give more emphasis on the training of the offense tactic because when there's a sequence of situations from fast break to early offense and set play, the offense become more effective, and reduces the probability of turnover (Bellotti, 1988; Brown, 1993; Dean, 1996; Motta, 1986; Tsamourtzis et. al.,1998) We found that both winners and losers made similar turnover percentage. This result is consistent with recent studies which we found that the turnover in relations to the offensive tactics doesn't seem to have affected the result of the game (Tsamourtzis et. al, 2001)

The fact that the area with the largest frequency of turnover was the perimeter area $(44.2 \%)$ is possibly due to a high mobility of players and ball. The area around the three-point line showed directly the highest percentage $(22.9 \%)$, and the restricted area followed (14.3\%). Significantly, the $81.4 \%$ of turnovers was made in the perimeter around the basket. Even more interesting was the fact that passing errors mainly happen away from the basket [three-point area 
(70.2\%), mid-court (44.6\%), backcourt (55.7\%)]. Finally, traveling (66.6\%), ball handling errors (41.4\%) and offensive fouls (69.1\%) showed the largest percentage in the perimeter area. To have knowledge of the above mentioned evidence, may help the coaches have more organized practices and system designs.

Finally, it seems that the ability to play effectivly against the defense zone was crucial for the win, as the losers showed the highest percentage turnovers $(22.2 \%)$ in dealing with this type of defense, whereas the winners the least $(16.5 \%)$. This fact should be given special attention to from the coaches as the above defense is used for long periods in the games (Theoxaropoulos et. al, 2002). Also important is the difference the winners and losers showed in dealing with man to man trapping defense. The above results match the works of Tsamourtzis et. al (2001), where there is a weakness of the defeated in dealing with these defenses. Nevertheless, there needs to be a more systematical study towards this direction because of the low frequencey shown this type of defense during the game.

\section{Conclusions - Proposals}

In the future, the coaches should spend more time practicing passing skills and ball handling, if they want to reduce their team's turnover percentages and improve significantly their offensive performance, as reducing the turnovers means increasing the chances of effective ball possesion. While taking into account the areas of the court where the turnovers occur and the type of turnover that occurs in each area, enables the coaches of the women's teams to prepare most effective systems, adapted specifically to women's basketball and to organize and guide better their practices. Also, we believe that the coaches of women's basketball should dedicate more time practicing defense zone because this strong defense zone is one fact that could affect the result of the game. Respectively speaking, there should be very good preparation by the team to deal with defense zones as they are commonly used in women's basketball.

Further research in relations to turnovers and parameters that are affecting their appearance, should be done in the future, so that to develop a more comprehensive image of the circumstances under which they occur. At the same time, with regard to women's basketball, in the future there should be a more systematic effort to identify specific features of the game, both in terms of turnover and shooting, fouls, offensive tactics defense, etc. 


\section{Bibliography}

Anastasiadis, M., (1995). Basketball Coaching. Symptosis. Athens.

Bellotti, R. S. (1988). The new statistics. In: R. S. Bellotti (Eds), Basketball's Hidden Game Points Created, Boxscore Defense, and other Revelations (pp., 1-54). New Brunswick: Night Work Publishing Co.

Brown, H. (1993). International Seminar of Training for Coaches. 12-15 April, Athens.

Dean, O. (1996). The Effect of Controlling Tempo. Journal of Basketball Studies. http://www. tsoft.com/ deano/.

Dean, O. (1997). Learning the Game. Journal of Basketball Studies. http://www. tsoft.com/ $\sim$ deano/.

DiNucci, J.M., Finkenberg, M.E., McCune, S.L, McCune, E.D., Mayo, T. (1994). Analysis of body esteem of female collegiate athletes. Perceptual and Motor Skills, 78(1), 315-319.

Elliot, B. (1992). A kinematic comparison of the male and female two point and three point jumps shot in basketball. Australian J. of Science \& Medicine in Sport, 24(4), 111-118.

Kioumourtzoglou E., Taxildaris K., Tsitskaris G. (1994). Team offense. Thessalo noki: Salto

Kundstadt, M. (1994). Fundamentals is the name. In J. Krause (Ed.), Coaching basketball. Indianapolis, IN: Master Press.

Looney, M. A., Spray, J. A., Castelli, D. (1996). The task difficulty of free throw eshooting for males and females. Research Quarterly for Exercise and Sport, 67(3), 265-271.

Mavridis G., Laios A., Taxildaris K. \& Tsiskaris G. (2003). Developing Offense in Basketball After A Return Pass Outside As Crucial Factor Of Winning. Inquiries in Sport \& Physical Education, 2 (1), 81-86.

Mavridis G., Tsamourtzis E., Karipidis A., \& Laios A. (2009). The inside game in World Basketball. Comparison between European and NBA teams. International Journal of Performance Analysis in Sport, 9(2), 157-164 (8) [On-line] 
Available: http://www.ingentaconnect.com/content/uwic/ujpa/2009/0000 0009/00000002;jsessionid=5esnbl168978b.alice

Mikes, J. (1987). A Computer Breakdown of Percentage Basketball. Scholastic Coach, 57(4), 12, 14.

Mikes, J. (1988). Percentage Basketball: the percentage favor the team that can fastbreak the oponents and prevent them from doing the same. Scholastic Coach, 57(6), 82,84.

Motta, D. (1986). The man-to-man set offense. In:. Basketball: The NBA Coaches Handbook (pp. 36-46). Prentice Hall Inc. Englewood Cliffs, N.J.

Polykratis, M., Tsamourtzis, E., Karypidis, A., Mavridis, G., \& Christodoulos, A. (2009). Pick n' Roll Efficacy and Variations between the National Teams of Greece and USA in the Semi-Finals of Mundobasket 2006 in Japan. Inquiries in Sport \& Physical Education, 7(1), 63-71, http:// hape.gr/emag.asp

Stavropoulos, N., Gerodimos, B., Tzouvaris, G., \& Kellis S. (2001). Basic passing types in the maximisation of success in the modern Basketball. Athletic performance and Health, III(3), 167-173.

Theoxaropoulos, A., Tsitskaris, G., \& Garefis A., (2002). Types of passing and their effectiveness in female basketball. Woman and Sport, I(1), 59-68.

Tsamourtzis, E., Filaktakidou, A., Arvanitidou, T., Ellinoudis T., \& Taxildaris K., (1998). Turnovers on offense in Greek basketball. Exercise \& Society Journal of sports science, 20, 248.

Tsamourtzis, E., Fylaktakidou, A., \& Taxildaris, K. (2001). The role that the time of the offensive duration plays to the efficacy of a basketball team. Exercise \& Society Journal of sports science, 27, 32-43.

Tsimpiris, A., Tsamourtzis E., Sfingos N., Zaggelidis G, Zaggelidis S. (2006). A multimedia application for tactic analysis of basketball games. Stïnta sportlui, 52: 17-39.

Tsitskaris G., Theoxaropoulos, A., Vamvakoudis, E., \& Nikopoulou M., (2001). Frequency and success of five different shot types between men and women athletes of basketball. Athletic performance and Health, III(2), 105-116. 
Anastassia FYLAKTAKIDOU, Ph.D. is a member of the Special Teaching Staff of University of Ioannina, Greece. She received a Ph.D. in Physical Education, from Democritus University (Department of Physical Education \& Sport Sciences), of Thrace, Hellas. She is interested in team sports and has worked as coach for basketball many years.

Evangelos TSAMOURTZIS, Ph.D. is an Assistant Professor of the Department of Physical Education \& Sport Sciences, Democritus University of Thrace, in basketball. He received a Ph.D. in Physical Education, from Democritus University (Department of Physical Education \& Sport Sciences), of Thrace, Hellas. His research interests involve the coaching and new technologies. He is an author or co-author of many scientific papers. E-mail address: etsamour@phyed.duth.gr

George ZAGGELIDIS, Ph.D. is an Assistant Professor of the Department of Physical Education \& Sport Sciences, Aristotle University of Thessaloniki (Hellas), is specialized in judo-karate. He received a Ph.D in Pedagogy (Sport), from University of Bucharest (Department of History-philosophy), Romania. His research interests involve Sport Pedagogy, coaching and combat sports. He has published as author or co-author numerous papers. E-mail address: gzangel@phed.auth.gr 